\title{
O STRICTO SENSUEM ÁREAS ESPECÍFICAS E AS PRÁTICAS DOCENTES DE PROFESSORES BACHARÉIS NO ENSINO SUPERIOR
}

\author{
Bruna Donato Reche \\ Maura Maria Morita Vasconcellos ${ }^{2}$
}

Resumo: Este artigo é um recorte de uma dissertação de Mestrado em Educação sobre formação de professores para o Ensino Superior, a partir do problema de pesquisa: Qual a perspectiva dos alunos oriundos do bacharelado sobre a formação para a docência no Ensino Superior desenvolvida no Mestrado em Educação de uma universidade pública?, visando analisar a perspectiva dos alunos bacharéis de Mestrado em Educação sobre formação para a docência no Ensino Superior. Neste artigo, o objetivo trata em refletir sobre práticas docentes de professores bacharéis do Ensino Superior, relativas às suas formações no stricto sensu. Foram levantadas informações, por meio de questionários, de 24 docentes bacharéis, 14 com formação no stricto sensu em áreas específicas e $10 \mathrm{em}$ mestrado acadêmico em Educação, referentes à formação profissional, conhecimentos e experiências consideradas importantes à docência, contribuições dos cursos stricto sensu e as dificuldades enfrentadas na docência. A metodologia de pesquisa privilegiou abordagem de cunho predominantemente qualitativo, de caráter exploratório-descritivo (MINAYO, 1994). Dentre os resultados, verificou-se que os apontamentos dos participantes são muito semelhantes quando se referem aos desafios da docência. Entretanto, as contribuições dos cursos stricto sensu frequentados exerceram diferentes influências nos conhecimentos e experiências que esses bacharéis têm como fundamentais ao magistério.

Palavras-chave: Docência no ensino superior. Formação docente. Docência por bacharéis.

\footnotetext{
${ }^{1}$ Instituto Federal Catarinense - campus Rio do Sul, Mestra em Educação, E-mail: bruna.reche@ifc.edu.br

${ }^{2}$ Universidade Estadual de Londrina - Departamento de Educação, Doutora em Educação,

E-mail:mmorita@uel.br
} 


\section{THE STRICT SENSE IN SPECIFIC AREAS AND PEDAGOGICAL PRACTICES FROM BACHELORS TEACHERS IN HIGHER EDUCATION}

Abstract: This article it's a piece of a master's of Education thesis about teacher training for hight education based on the research problem: What is the perspective of bachelor's students about teacher education developed in the Masters in Education from a public university?, for the pourpose of to analyze the perspective of bachelors students from the master's Education in States University of Londrina about teaching training in higher education. Specifically in this article, the goal is to analyze the practices of bachelors teachers in higher education, regarding their educational backgrounds in the strict sense. The information from 24 bachelors were gathered through questionnaires, 14 teachers who trained in the strict sense specific academic areas and ten Masters in Education, relating to vocational training, knowledge and experience considered important to teaching, contributions of the strict sense courses and the difficulties faced in the teaching profession. The research methodology was predominantly qualitative, exploratory and descriptive (MINAYO, 1994). Among the results, it was found that the notes of the participants are very similar when referring to the challenges of teaching. However, the contributions of strict sense courses frequented exerted different influences on the knowledge and experiences that these bachelor's graduates have as fundamental to teaching.

Keywords: Teaching by bachelors. Teacher training. Teaching in higher education

\section{EL STRICTO SENSU EN ÁREAS ESPECÍFICAS Y LAS PRÁCTICAS DOCENTES DE PROFESORES BACHARÉIS EN LA ENSEÑANZA SUPERIOR}

Resumen: Este artículo proviene de una disertación de maestría en Educación sobre formación para la educación superior, basada en el problema de investigatión: ¿Cuál es la perspectiva de los estudiantes bachilleres sobre la formación de docentes desarrollada en el Márter en Educación de una universidad pública?, con ele objetivo de analizar la perspectiva de los estudiantes bachilleres de la Universidad Estadual de Londrina sobre la formación docente en la educación superior. En este artículo, el objetivo es reflexionar sobre las prácticas docentes de profesores bachilleres de la enseñanza superior, relativas a sus formaciones en el stricto sensu. Se analizaron los resultados obtenidos en el análisis de los resultados obtenidos en el análisis de los resultados obtenidos en el estudio, las dificultades enfrentadas en la profesión docente. La metodología de investigación privilegió el enfoque de cuño predominantemente cualitativo, de carácter exploratorio-descriptivo (MINAYO, 1994). Entre los resultados, se verificó que los apuntes de los participantes son muy similares cuando se refieren a los desafíos de la docencia. Sin embargo, las contribuciones de los cursos stricto sensu frecuentados ejercieron diferentes influencias en los conocimientos y experiencias que estos bachilleres tienen como fundamentales al magisterio.

Palabras clave: Docencia en la enseñanza superior. Formación docente. Docencia por bachilleres. 
Introdução

Esse artigo apresenta um recorte de uma dissertação de Mestrado em Educação que objetivou compreender a percepção dos bacharéis em um programa de Mestrado em Educação de uma universidade pública no sul do país sobre a formação pedagógica docente para o Ensino Superior.

Em pesquisa com a secretaria do Programa de Mestrado em Educação da UEL foram coletadas informações referentes aos alunos matriculados nas turmas de 2009 a 2014, tais quais nomes, e-mails e formação superior. Do total de 190 alunos matriculados nesse período, trinta e quatro apontaram como formação inicial área de bacharelado.

Esses alunos foram contatados pelo e-mail informado e também pela rede social Facebook para participarem do levantamento de dados sobre o tema da pesquisa por meio do questionário com questões abertas. Foram ao todo 16 participantes, com predomínio daqueles oriundos das turmas de 2012 e 2014.

Os dados que embasam este texto evidenciaram algumas práticas docentes de professores bacharéis do ensino superior com formação no stricto sensu em áreas de formação inicial e na área da Educação. Além disso, ainda que de forma restrita, permitiram analisar aspectos relacionados aos interesses, ao ingresso à carreira docente, à formação profissional e aos conhecimentos da profissão docente dos participantes.

A carreira docente no Ensino Superior está em expansão tanto como mostra os estudos de Velloso (2004) quanto pelo crescente número de criações de instituições particulares no país apontado por Michelotto, Zainko e Andrich (2006). Decorrente disso, a importância de estudos que abordem a docência no Ensino Superior desenvolvida por bacharéis e o aprofundamento de saberes que possam descrever, ainda que de forma particular, o percurso profissional docente destes sujeitos.

A pesquisa foi realizada por meio de dois questionários, um voltado para docentes bacharéis com formação na pós-graduação stricto sensu em área de Formação Inicial e outro a docentes bacharéis que optaram por realizar o mestrado acadêmico na área da Educação, de instituições públicas e privadas na cidade de Londrina, interior do Estado do Paraná. 0 intuito foi analisar semelhanças e 
diferenças entre as respostas dos dois grupos de docentes com formações distintas no stricto sensu, com vistas a compreender suas práticas docentes.

Segundo Richardson (2007), os questionários possibilitam o levantamento de informações de um grande número de pessoas, apresenta relativa uniformidade de informações, facilidade de tabulação dos dados e abrangência de amplas áreas geográficas em tempo relativamente curto. Para a interpretação dos dados, a proposta de Minayo; Assis e Souza (2005) foi a escolhida, uma vez que valoriza a comunicação e a linguagem entre os sujeitos na análise dos dados.

Três questões importantes foram feitas a eles: quais conhecimentos e experiências eles consideravam importantes para a docência; as contribuições dos cursos stricto sensu para a carreira docente e as dificuldades enfrentadas na profissão docente. A análise dessas questões permitiu identificar semelhanças e diferenças na prática docente desses bacharéis que possuem cursos de pós-graduação em áreas específicas e da Educação.

0 estudo foi realizado predominantemente pela perspectiva da pesquisa qualitativa, de caráter exploratório-descritivo, visando compreender suas práticas docentes, de acordo com suas distintas formações no stricto sensu. Este modelo de pesquisa identifica-se com o problema levantado neste estudo, pois aborda "o conjunto de expressões humanas constantes nas estruturas, nos processos, nos sujeitos, nos significados e nas representações” (MINAYO, 1994, p. 15).

\section{Desafios da Carreira Docente no Ensino Superior e o Compromisso com a Formação Profissional e Humana}

A docência no Ensino Superior caracteriza-se na dinâmica entre pesquisa, produção de conhecimento e deste sobre o ensino, adaptando às características dos alunos e culminando aos objetivos da instituição. Ademais, confere-se na complexidade das ações dos sujeitos envolvidos, das interferências políticas e administrativas, das construções e aprendizados que constantemente incorporam elementos às concepções e atitudes docentes.

Como afirma Dias Sobrinho (2005), a universidade é requerida por interesses profundamente divergentes e contraditórios da própria sociedade, sendo necessário, portanto, discernimento e isenção de influências para avaliar o que é proposto à 
universidade atualmente e o que realmente está imbuído a ela exercer em prol do desenvolvido cognitivo, ético e social.

Segundo Oliveira e Vasconcellos (2011), ao professor cabem os atos de ensinar, produzir e disseminar conhecimentos entre outros aspectos exigidos, para que o compromisso de desenvolvimento social pela universidade ocorra. A carreira docente demanda participação no processo de formação humana discente e docente que requer diagnósticos e planejamentos coerentes com o propósito de emancipação intelectual, científica e cultural (OLIVEIRA; VASCONCELLOS, 2011). Essa formação ocorre na interação complexa dos campos de conhecimento, científicos e tecnológicos (CUNHA, 2000).

0 trabalho docente, assim, precisa ser desenvolvido por esforços teóricos e práticos em articular formação e pesquisa, epistemologia e pedagogia dentro de plurais práticas sociais e investigativas que não mais se bastam de conhecimentos estritamente científicos e necessitam de outros advindos dos diversos contextos e modos de saber (CUNHA, 2000).

Diante desta conduta docente, alguns desafios são necessários de enfrentamento como: o reconhecimento das limitações do modelo clássico da universidade frente às novas demandas do mercado que exigem uma conduta crítica que não cause a resistência ou submissão extrema, mas que conduza as práticas institucionais (MICHELOTTO; ZAINKO; ZAINKO, 2006).

Além da necessidade de pensar o papel da instituição e do professor no que tange aos saberes e competências, antes considerados imponentes e que hoje passam por um processo de destituição, obsolescência, fragmentação e insuficiência, requeridos pelo mundo contemporâneo (RIBEIRO; CUNHA, 2010). E disso as práticas de ensino voltadas para os objetivos propostos e o embate das novas exigências do mercado de trabalho que interferem nos valores políticos, educacionais e culturais da profissionalização ofertada (FAGUNDES; BROILO; FORSTER, 2008)

Os professores do Ensino Superior são cada vez mais responsabilizados pelo sucesso da profissão em que contribuem, na medida em que investigam a área. No entanto, a preparação para a docência voltada para a pesquisa, não subsidia condições para que os insumos sejam revertidos na formação discente. Isso porque: "[...] a inexistência de qualquer teorização sobre a dimensão pedagógica os torna 
profissionalmente frágeis, assumindo um papel profissional para o qual não possuem saberes sistematizados" (CUNHA, 2010, p. 2).

Ao que Anastasiou (2006) percebe, apesar do domínio em área de conhecimento, os professores têm poucas oportunidades em compreender, de fato, os conceitos essenciais, leis básicas, princípios organizadores, relações e nexos que as disciplinas que ministram possibilitam como campo de atuação e ensino, quando há a necessidade de elencar os elementos determinantes do conhecimento e traduzi-los em saberes escolar e profissional possíveis de ensino.

Além do mais, como destaca Morosini e Morisini (2006), existe uma fragilidade envolta dos conhecimentos, estratégias e técnicas profissionais docentes devido à ausência de referenciais que sejam consensuais à profissão. Essa crise evidencia-se desde a insatisfação quanto à formação oferecida nas instituições de ensino que não condizem com a realidade profissional e atinge o professorado marcado pela ambiguidade do trabalho entre profissionalismo e proletarização, além da falta de reconhecimento social e mal-estar docente.

Esses desafios mostram que a docência no Ensino Superior precisa ser construída dinamicamente na superação da lógica pragmática e utilitária de conhecimento (FAGUNDES; BROILO; FORSTER, 2008) e em conjunto com os sujeitos institucionalmente envolvidos como colegas de trabalho, alunos e os demais, a fim do desenvolvimento profissional (OLIVEIRA; VASCONCELLOS, 2011).

Pautado em Isaia (2006) e Goergen (2006), que discutem os desafios e questões postas para a docência no Ensino Superior e os objetivos e compromissos da universidade, afirma-se que a universidade tem como propósito a construção da cidadania por meio do trabalho docente de formação de sujeitos críticos e reflexivos. No sentido, proposto por Morin (2003, p. 103) em:

[...] fornecer uma cultura que permita distinguir, contextualizar, globalizar os problemas multidimensionais, globais e fundamentais, e dedicar-se a eles; [...] também promovendo nelas a inteligência estratégica e a aposta em um mundo melhor.

A docência é uma profissão complexa que requer conhecimentos específicos e habilidades pedagógicas para o manejo de ensino. 0 início da docência é um período de conversão em ser professor, determinante para o desenvolvimento profissional coerente e progressivo (ISAIA; MACIEL; BOLZAN, 2010). Como caracterizam as 
autoras, os primeiros anos da profissão são voltados à aprendizagem de como ensinar no contato com os alunos e com o conhecimento que se tem sobre a disciplina, além do mais, constituem-se como um momento importante de socialização profissional e profissionalismo interativo.

Atuando na docência no Ensino Superior encontram-se sujeitos das mais diversas áreas, mas o que há de comum entre eles é que muitos contam com a formação específica e a experiência profissional, quando existe, para fundamentar as práticas de ensino e que poucos têm formação pedagógica universitária, pois a formação proporcionada pela licenciatura relaciona-se com a docência no Ensino Básico, que confira como elemento fundamental para o desenvolvimento das práticas de ensino e aprendizagem.

Ainda que se apresente com características distintas, para ser professor são necessários alguns entendimentos fundamentais à profissão. Segundo Castro (2012), ao professor é preciso o entendimento sobre o sentido e o alcance da apropriação de um referencial que legitime suas concepções; sobre o planejamento de caminhos para a realização dos objetivos; sobre a fragilidade das teorias e conhecimentos que se modificam e se alteram constantemente e, principalmente, como os sujeitos se relacionam no processo de ensinar e aprender.

$\mathrm{Na}$ ação de ser professor, a construção da identidade docente se fortalece sobre uma formação ambientada na troca de experiências, para que os aspectos pessoais e sociais desta identidade deem sentido à multiplicidade de papéis que ao docente é requisitado, consonante ao próprio indivíduo sobre suas ações e no reconhecimento de seus pares (SAINSANLIEU, 1995 apud JOAQUIM; VILAS BOAS; CARRIERI, 2012). Isso identifica o valor consubstancial da profissão enquanto trabalho que advém e culmina no social.

0 valor social da docência é maior do que qualquer outra profissão, pois, segundo Martins (2007 p. 5), seu produto não é material, quantificável, mas se revela na consolidação das condições de apropriação do conhecimento sistematizado por meio do contato social dos sujeitos: "[...]. 0 trabalho educativo pressupõe o homem diante de outro homem de quem não pode estar estranho (alienado), fundando-se numa relação que é por natureza interpessoal e mediada pelas apropriações e objetivações desses homens". Isso depende do saber consciente da área de 
conhecimento, do saber sobre as formas de aprendizagem e auxílio de ensino aos alunos.

As relações construídas dentro do campo educativo promovem valores, atitudes e ações que podem e devem resultar em uma sociedade melhor, por isso é uma profissão social e deve ser permeada de aspectos que valorizem essa dimensão. Pertinente é a reflexão de Luz e Balzan (2012, p. 26) sobre o artigo de Pereira ([2007]):

[...] a qualidade de ensino e/ou a melhoria dos resultados de uma gestão universitária só têm sentido se chegarem até a sala de aula, se atingirem 0 processo de ensino e aprendizagem e 0 inter-relacionamento professor e aluno, e se constituírem num instrumento de construção de um profissional cidadão. Cidadão esse entendido como aquele que se especializa consoante as competências, habilidades e atitudes requeridas pelo mercado, mas, também e principalmente, por aquele profissional que colabore para a existência de um mundo mais humano, mais solidário, mais justo, mais ativo e significativo em seu tempo presente (LUZ; BALZAN, 2012, p. 26).

Esse é o ponto essencial de compreensão sobre a profissão docente: a formação de cidadãos que compõem a sociedade, com vistas em seu desenvolvimento e melhoria das relações humanas.

Construir relações sociais a partir da construção de conhecimento torna a universidade lugar privilegiado na formação de humanos conscientes e comprometidos com o bem comum e com as questões que afligem a sociedade. Além do mais, ao contribuir para a profissionalização discente, que para Morin (2003, p. 65) significa “ensinar a assumir a condição humana, ensinar a viver”, também o faz para a solidariedade, a responsabilidade social e o respeito.

A valorização da ética, da crítica, da solidariedade e da equidade social, aspectos humanos para a formação profissional proporcionada, vale-se das palavras de Isaia, Maciel e Bolzan (2010, p. 13), quando afirmam que "[...] acreditamos que os domínios do conhecimento específico, de estratégias didáticas e recursos tecnológicos não suprirão a formação pedagógica, humana e ética inerentes à profissão docente mesmo sendo necessários".

Uma orientação que articula as relações de ensino, os aspectos pedagógicos e conhecimentos contribuintes das diversas áreas fazem-se necessário quando há a intenção de formação humana, além de profissional. 
As Diferentes Formações no Stricto Sensu e as Práticas Docentes de Professores Bacharéis no Ensino Superior

A pesquisa investigou as práticas docentes de bacharéis no Ensino Superior, tendo como sujeitos os bacharéis docentes com formação stricto sensu em áreas específicas de conhecimentos e bacharéis docentes que optaram pelo mestrado acadêmico na área da Educação, de instituições públicas e privadas da cidade de Londrina, interior do Estado do Paraná.

As trajetórias de formação dos docentes participantes são distintas, dessa forma, a pesquisa contou com dois questionários, um voltado para docentes bacharéis no Ensino Superior com formação no stricto sensu em áreas específicas e outro para docentes bacharéis oriundos do Mestrado acadêmico em Educação. Esses questionários permitiram identificar a pluralidade de saberes que a formação e a prática profissional convergem à carreira docente.

O levantamento de dados sobre a docência dos bacharéis com formação stricto sensu em área inicial contou com quatorze participantes, oito homens e seis mulheres. Enquanto que o levantamento de dados sobre a carreira docente dos bacharéis oriundos do Mestrado acadêmico em Educação contou dez participantes, três homens e sete mulheres. Ao todo, portanto, foram vinte e quatro docentes respondentes, onze homens e treze mulheres (QUADRO 1).

As áreas de Formação Inicial dos participantes são: Administração, Ciência da Computação, Educação Física, Engenharia da Computação, Engenharia Têxtil, Farmácia, Fisioterapia, Fonoaudiologia, Jornalismo, Odontologia, Psicologia, Secretariado Executivo e Serviço Social (QUADRO 1).

Sobre a formação profissional destes docentes: dois são doutores em áreas de Formação Inicial, quatro são doutorandos também em áreas de Formação Inicial, nove são mestres, sendo seis em Educação e nove são mestrandos, em que quatro em Educação e quatro em áreas específicas (QUADRO 1).

A idade dos participantes com formação stricto sensu em áreas específicas varia: sete tem entre 25 a 30 anos e seis tem idade entre 30 e 40 anos. Já os participantes bacharéis oriundos do Mestrado em Educação tem a idade variante: três entre 30 e 35, cinco entre 35 e 40 e um com 42 anos (QUADRO 1). 
Essa diferenciação de idade entre os participantes leva a crer que é mais frequente que o bacharel recém-formado curse o stricto sensu em áreas da Formação Inicial enquanto os bacharéis docentes que optam por cursar o mestrado em Educação levam tempo maior, provavelmente de consolidação de suas carreiras docentes.

Esse último dado também é visualizado devido ao tempo de serviço na carreira dos participantes, que é maior para os oriundos do Mestrado em Educação. Entre os docentes bacharéis com formação stricto sensu específica: seis menos de um ano, dois tem um ano, um tem dois anos, um tem três anos, um tem quatro anos, um tem seis anos e dois tem mais de dez anos. Entre os docentes bacharéis oriundos do Mestrado em Educação: um tem dois anos, dois tem três anos, dois tem cinco anos, um tem sete anos, dois tem dez anos, um tem quatorze anos e um tem quinze anos (QUADRO 1).

Esses dados estão apresentados no quadro 1 a seguir, divididos entre os docentes com formação no stricto sensu em áreas específicas e na Educação:

Quadro 1 - Características gerais dos participantes

\begin{tabular}{|c|c|c|}
\hline Características & $\begin{array}{c}\text { Com stricto sensu em áreas } \\
\text { específicas }\end{array}$ & $\begin{array}{c}\text { Com stricto sensu na área da } \\
\text { Educação }\end{array}$ \\
\hline Sexo & $\begin{array}{l}8 \text { homens } \\
6 \text { mulheres }\end{array}$ & $\begin{array}{l}3 \text { homens } \\
7 \text { mulheres }\end{array}$ \\
\hline Idade & $\begin{array}{l}7 \text { entre } 25 \text { a } 30 \text { anos } \\
6 \text { entre } 31 \text { e } 40 \text { anos } \\
1 \text { mais de } 40 \text { anos }\end{array}$ & $\begin{array}{l}7 \text { entre } 30 \text { a } 40 \text { anos } \\
2 \text { com mais de } 40 \text { anos } \\
1 \text { com mais de } 50 \text { anos }\end{array}$ \\
\hline Áreas de formação inicial & $\begin{array}{l}\text { Odontologia, Educação } \\
\text { Física, Ciência da } \\
\text { Computação, Jornalismo, } \\
\text { Farmácia, Administração, } \\
\text { Serviço Social, Psicologia, } \\
\text { Fisioterapia e Secretariado } \\
\text { Executivo }\end{array}$ & $\begin{array}{l}\text { Administração, Engenharia } \\
\text { da computação, Engenharia } \\
\text { têxtil, Fonoaudiologia, } \\
\text { Psicologia, Secretariado } \\
\text { Executivo e Serviço Social }\end{array}$ \\
\hline Formação acadêmica & $\begin{array}{l}4 \text { mestrandos } \\
5 \text { mestres } \\
3 \text { doutores } \\
2 \text { doutorandos }\end{array}$ & $\begin{array}{l}4 \text { mestrandos } \\
6 \text { mestres }\end{array}$ \\
\hline Instituição de trabalho & $\begin{array}{l}6 \text { em instituições públicas } \\
8 \text { em instituições particulares }\end{array}$ & $\begin{array}{l}3 \text { em instituições públicas } \\
1 \text { em instituições pública e } \\
\text { privada } \\
6 \text { em instituições privadas }\end{array}$ \\
\hline Tempo de serviço & $\begin{array}{l}2 \text { há mais de } 10 \text { anos } \\
1 \text { há } 6 \text { anos } \\
5 \text { há menos de } 4 \text { anos } \\
6 \text { há menos de um ano }\end{array}$ & $\begin{array}{l}5 \text { há menos de } 5 \text { anos } \\
5 \text { entre } 7 \text { e } 15 \text { anos }\end{array}$ \\
\hline
\end{tabular}

Fonte: As autoras (2013) 

superior

0 interesse pela docência no Ensino Superior acompanha a maioria dos participantes desde a graduação. Ainda sim, a maioria ingressou na carreira docente após o curso de pós-graduação e, principalmente, por oportunidade de emprego.

Importante pergunta aos participantes foi feita referente às contribuições dos cursos de Pós-Graduação stricto sensu para a carreira docente dos participantes. Nela, a maioria dos participantes com cursos de Pós-Graduação nas áreas de Formação Inicial mencionou o aprofundamento de conhecimentos específicos como o domínio teórico-científico específico e o conhecimento da área voltado para o mercado de trabalho.

Além disso, para os profissionais bacharéis com formação em cursos stricto sensu em área específica de conhecimento a experiência em docência no Ensino Superior por meio de estágio supervisionado foi mencionada pela maioria, além do amadurecimento acadêmico proporcionado pelo curso.

Para a maioria dos docentes oriundos do Mestrado em Educação, a contribuição do curso de pós-graduação foi postura de reflexão crítica da profissão e maior confiança em sala de aula.

Outros participantes mencionaram aspectos didáticos como contribuições dos cursos stricto sensu frequentados. Para os oriundos de áreas específicas, alguns assinalaram a didática docente. Para os oriundos do Mestrado em Educação, alguns afirmaram maior atenção à organização e atenção aos problemas de aprendizagem, cautela nas formas de avaliação e zelo no processo de ensino e aprendizagem.

Tanto para os docentes com formação específica quanto para os docentes com formação no Mestrado em Educação, o conhecimento da pesquisa científica foi essencial aos cursos de mestrado e doutorado. Da mesma forma, para alguns respondentes, com ambas as formações, os cursos do stricto sensu não contribuíram com a profissão docente. Isso revela que é frequente a exaltação da pesquisa científica nos diversos cursos stricto sensu e que essa pode ser a justificativa para o pouco entendimento sobre formação docente promovido por eles.

Quando perguntado sobre quais os conhecimentos e experiências que os participantes julgam importantes e fazem parte da docência, tanto as respostas dos docentes bacharéis com formação no stricto sensu em áreas específicas quanto os que cursam ou cursaram o Mestrado na área da Educação permearam, principalmente, a didática e metodologias de ensino; os conhecimentos específicos oriundos dos cursos 
de formação e anteriores à profissão; experiências que influem a prática profissional; desenvolturas para a profissão docente e características que embatem na formação pedagógica.

Relacionado aos conhecimentos específicos, muitos participantes com Pós-Graduação na área de Formação Inicial os mencionaram. Por outro lado, não foram todos os respondentes docentes com Mestrado em Educação que os mencionaram, muitos elencaram a experiência e prática profissional com o conteúdo ministrado, bem como as experiências nos estágios e grupos de pesquisa, em apresentações de trabalhos, palestras e a experiência de vida e profissional na área.

Alguns docentes com formação somente em áreas específicas elencaram como importante o conhecimento sobre seus alunos, sobre os objetivos do Ensino Superior e papel da universidade. Além disso, outros citaram a comunicação com os alunos e compreensão da realidade.

As desenvolturas para a profissão docente ficaram evidentes quando a visão crítica e criativa e o conhecimento de recursos tecnológicos na sala de aula foram citados por alguns participantes com formação em área específica. Ainda sobre as desenvolturas para a profissão docente, os professores bacharéis com formação no Mestrado ou mestrandos em Educação mencionaram a oratória, a postura constante de busca do conhecimento e a atenção às falhas de colegas de profissão como elementos importantes para o desenvolvimento da docência.

Aspectos da formação profissional também foram elencados por alguns participantes com formação no Mestrado em Educação como a influência de parentes professores, a formação em magistério antes do bacharelado e a formação no Mestrado em Educação para seguir com a docência no ensino superior.

A última pergunta remeteu às dificuldades e desafios na profissão docente percebidas pelos participantes. Muitos aspectos foram abordados por eles, por isso foram elencados em categorias para melhor compreensão. As categorias desenvolvidas foram: desvalorização do magistério, relações interpessoais, aspectos didáticos, Formação Inicial e Continuada docente, conjunturas da profissão docente e adequação docente frente às novas tecnologias.

Nas menções em torno da desvalorização do magistério, os participantes elencaram aspectos semelhantes. Para os professores do Ensino Superior com 
formação no stricto sensu em áreas de Formação Inicial, o que mais dificulta a profissão é o baixo salário, principalmente de instituições particulares de ensino.

Além disso, muitos apontaram o excesso de trabalho; a necessidade de tempo extra de trabalho que não é remunerado, uma vez que o trabalho assalariado em instituições particulares e em alguns contratos em instituições públicas ocorre por meio da hora/aula; a pressão exercida para o cumprimento de prazos e atividades; a exaltação do comércio de aulas em detrimento do conhecimento e a educação mercadológica.

No mesmo sentido, dentre os participantes oriundos do Mestrado em Educação, os participantes elencaram a falta de reconhecimento da profissão docente; a primazia da carreira de pesquisador em detrimento da docência; a burocracia do ensino público e a instabilidade na profissão docente em instituições privadas.

Ainda na pergunta sobre as dificuldades enfrentadas na profissão docente, as respostas em torno da desvalorização do magistério dos docentes participantes oriundos do Mestrado em Educação relacionaram-se com a falta de reconhecimento da profissão pelas instituições sociais e políticas.

No ensino público, a profissão tem muita burocracia e no ensino privado a relevância da docência embate com a baixa remuneração dos docentes, como afirmam alguns participantes, além do ambiente empresarial e com a mercantilização da educação, mencionado por um.

Sobre as relações interpessoais, os participantes oriundos do Mestrado em Educação afirmaram que as maiores dificuldades dizem respeito aos alunos, principalmente quanto ao desinteresse durante as aulas. Outros mencionaram o desafio em manter o interesse deles nas aulas e a necessidade de adequação ao perfil do aluno. Além disso, foram apontadas a imaturidade de alguns deles em relação ao Ensino Superior, a fraca formação advinda do Ensino Médio e a falta de respeito ao professor.

Para os docentes com formação em suas áreas iniciais, a maioria reclamou da fraca formação advinda do Ensino Básico e também sobre a falta de interesse dos alunos nas atividades de ensino.

Ainda nas relações interpessoais, um dos participantes oriundos do Mestrado em Educação mencionou que um desafio ao cotidiano docente é a influência da desmotivação de colegas. 0 mesmo foi apontando por um docente bacharel com 
formação no stricto sensu em área específica ao afirmar que se sente afetado pela desmotivação e despreparo de colegas docentes.

Nas menções sobre os aspectos didáticos, alguns professores com formação específica revelaram dificuldades no ensino com o perfil profissional em constantes mudanças e dificuldades em envolver os alunos nas atividades. Outros mencionaram sentirem falta de conhecimentos pedagógicos, dificuldades em mostrar aplicação prática do conteúdo de ensino e também que a metodologia de ensino não condiz com o perfil profissional esperado.

Da mesma forma, os professores oriundos do Mestrado em Educação também fizeram apontamentos como o desafio em desenvolver um ensino de qualidade, em transmitir experiências e conhecimentos, em demonstrar a importância da disciplina, bem como sua prática.

Referente à Formação Inicial e Continuada docente, alguns participantes com formação no Mestrado em Educação responderam como desafios a necessidade de atualização constante dos conhecimentos, a Formação Inicial fraca para a docência e para as demandas do papel de pesquisador. Para outros docentes, com formação em áreas iniciais, a falta de incentivo à profissionalização do professor nas instituições também é um desafio.

Quanto às conjunturas da profissão docente, participantes oriundos do Mestrado em Educação mencionaram as instalações físicas das instituições como não adequadas ao ensino e outros afirmaram a falta de tempo para estudos e pesquisas e 0 excesso de trabalho. Da mesma forma, professores com formação stricto sensu em áreas específicas reclamaram da estrutura física das instituições em que são docentes.

Sobre a adequação docente frente às novas tecnologias, alguns docentes bacharéis oriundos do Mestrado em Educação afirmaram o desafio de adaptarem-se a elas e outro afirmou como desafio o fazer docente nas modalidades presencial e a distância de educação, como o próprio docente afirmou. No mesmo sentido, um docente bacharel doutorando em sua área de Formação Inicial apontou a dificuldade em manter a atenção dos alunos diante das tecnologias móveis como celulares, tablets e notebooks dos alunos. 


\section{Conclusão}

Ao analisar as respostas dos participantes, ficou evidente que os apontamentos são muito semelhantes quando se referem aos desafios enfrentados na profissão docente. Entretanto, percebe-se que as contribuições dos cursos de Pós-Graduação frequentados são diferentes e exercem diferentes influências nos conhecimentos e experiências que esses bacharéis têm como fundamentais à docência.

Duas perspectivas são importantes de se considerar, por meio da análise dos dados coletados dos participantes: a preocupação intrínseca com a formação relativa aos conhecimentos pedagógicos, no intuito de uma prática docente coerente com as contribuições das diversas áreas educacionais e a preocupação extrínseca de aprofundamento de conhecimentos que permeiam o contexto docente, na tentativa de melhorarem suas práticas profissionais por determinação ou influência de outrem. Outra perspectiva é o currículo, uma vez que o Mestrado em Educação confere a apreciação de aprofundamento científico e domínio nos conteúdos pedagógicos que possibilitem a atuação mais pontual em comissões, coordenações e direções acadêmicas.

Entretanto, ao cursarem o Mestrado em Educação, muitos perceberam que estas perspectivas iniciais foram resultados de um percurso acadêmico e profissional com lacunas quanto à importância do conhecimento pedagógico para a atuação docente e, por outro lado, que, no stricto sensu, enfático na pesquisa científica, essa necessidade não seria suprida, mas contornada, evidenciando caminhos mais coerentes, como a construção da carreira pedagógica no coletivo, possibilitando ferramentas de estudo nas diversas áreas correlacionadas, contribuindo com a formação de práticas científicas que facilitam esse estudo e, sobretudo, tornando-os mais críticos sobre a complexidade da carreira docente no Ensino Superior que é múltipla em fatores, mas que imprescinde do objetivo claro sobre os fins e os meios da formação profissional, considerando as reais possibilidades e o estudo aprofundado sobre sociedade e o papel do Ensino Superior e, por conseguinte, o aporte pedagógico das inúmeras áreas que debruçam-se em investigar fatores do processo de ensino e aprendizagem, ademais à atualização constante no conhecimento específico que, para muitas instituições ainda é compreendida como única e prioritária mas que, com o auxilio de 
pesquisas como desta natureza, elucidam, cada vez mais, a preocupação com o Ensino Superior coerente com suas funções sociais.

Quando indagados sobre as contribuições dos cursos de Pós-Graduação stricto sensu, a maioria dos participantes com formação em áreas específicas mencionaram aspectos sobre o conhecimento específico, enquanto que os participantes docentes oriundos do Mestrado em Educação apontaram a reflexão crítica da profissão, organização, cautela e zelo pelo processo de ensino e aprendizagem.

Semelhante a essas respostas também foram as da questão sobre os conhecimentos e experiências importantes à docência, em que para doze dos participantes com stricto sensu em áreas específicas para ser docente é necessário ter o conhecimento específico, enquanto três participantes oriundos do Mestrado em Educação mencionaram o mesmo.

Desses dados, conclui-se que os desafios na carreira docente são os mesmos para professores, independentemente de sua Formação Inicial, mas o enfrentamento dessas questões está fortemente relacionado ao caráter da formação profissional obtida no stricto sensu.

A pluralidade de saberes que caracterizam as práticas docentes é fundamental e os diferentes caminhos de formação profissional são exímias fontes desses saberes. Cabe descobrir, para além, se há espaços para que essas diferenças possam ser discutidas entre os professores a fim de uma docência cada vez mais comprometida.

\section{Referências}

ANASTASIOU, L. G. Docência na educação superior. In: RISTOFF, D.; SAVEGNANI, P. (org.). Docência na educação superior. Brasília: INEP, 2006. p. 147-172.

CASTRO, R. M. A pós-graduação em educação no Brasil: alguns aspectos à luz de estudos realizados na área. Educação em Revista, Belo Horizonte, v. 28, n. 4, p. 263-287, dez. 2012.

CUNHA, M. I. Ensino como mediação da formação do professor universitário. In: MOROSINI, M. C. (org.). Professor do ensino superior: identidade, docência e formação. Brasília: INEP, 2000. p. 45-53.

CUNHA, M. I. O campo da iniciação à docência universitária como um desafio. In: REUNIÃO ANUAL DA ANPED, 33., 2010, Rio de Janeiro. Anais [...]. Rio de Janeiro: ANPED, 2010. Disponível em:

http://33reuniao.anped.org.br/33encontro/app/webroot/files/file/Trabalhos\%20em \%20PDF/GT04-6134--Int.pdf.Acesso em: 5 set. 2013. 
DIAS SOBRINHO, J. Dilemas da educação superior no mundo globalizado: sociedade do conhecimento ou economia do conhecimento?. São Paulo: Casa do Psicólogo, 2005.

FAGUNDES, M. C. V.; BROILO, C. L.; FORSTER, M. M. S. É possível construir a docência universitária? Apontamos caminhos. In: REUNIÃO ANUAL DA ANPED, 31., 2008, Caxambu. Anais [...]. Caxambu: ANPED, 2008. p. 1-16.

GOERGEN, P. Universidade e compromisso social. In: RISTOFF, D.; SAVEGNANI, P. (org.). Universidade e compromisso social. Brasília: Instituto Nacional de Pesquisas Educacionais Anísio Teixeira, 2006. p. 65-95.

ISAIA, S. M. A.; MACIEL, A. M. R.; BOLZAN, D. P. V. Educação Superior: a entrada na docência universitária. In: REUNIÃO ANUAL DA ANPED, 33., 2010, Rio de Janeiro. Anais [...]. Rio de Janeiro: ANPED, 2010. Disponível em: http://33reuniao.anped.org.br/33encontro/app/webroot/files/file/Trabalhos\%20em \%20PDF/GT08-6411--Res.pdf. Acesso em: 9 set. 2013.

ISAIA, S. M. A. Desafios à docência superior: pressupostos a considerar. In: RISTOFF, D.; SAVEGNANI, P. (org.). Docência na educação superior. Brasília: INEP, 2006. p. 63-84.

JOAQUIM, N. F.; VILAS BOAS, A. A.; CARRIERI, A. P. Entre o discurso práticado e a realidade percebida no processo de formação docente. Avaliação, Campinas, v. 17, n. 2, p. 503-528, jul. 2012.

LUZ, S. P.; BALZAN, N. C. Programa de formação continuada para docentes da educação superior: um estudo avaliativo a partir dos resultados de uma tese. Avaliação, Campinas, v. 17, n. 1, p. 11-41, mar. 2012.

MARTINS, L. M. A formação social da personalidade do professor. um enfoque vigotskiano. Campinas: Autores Associados, 2007.

MICHELOTTO, R. M.; ZAINKO, M. A. S.; ANDRICH, E. G. Educação superior no Paraná 1991 - 2004. In: RISTOFF, D.; GIOLO, J. (org.). Educação superior brasileira: 1991-2004. Brasília: INEP, 2006. p.21-70.

MINAYO, M. C. S. Ciência, técnica e arte: o desafio da pesquisa social. In: MINAYO, M. C. S. (org.). Pesquisa social: teoria, método e criatividade. Petrópolis: Vozes, 1994. p. 9-29.

MINAYO, M. C. S.; ASSIS, S. G.; SOUZA, E. R. Avaliação por triangulação de métodos: abordagens de programas sociais. Rio de Janeiro: Fiocruz, 2005.

MORIN, E. A cabeça bem-feita: repensar a reforma, reformar o pensamento. 8. ed. Rio de Janeiro: Bertrand Brasil, 2003.

MOROSINI, M. C.; MOROSINI, L. Pedagogia universitária: entre a convergência e a divergência na busca do alomorfismo universitário. In: RISTOFF, D.; SAVEGNANI, P. Docência na educação superior. Brasília: INEP, 2006. p. 47-63.

OLIVEIRA, C. C.; VASCONCELLOS, M. M. M. A formação pedagógica institucional para a docência na Educação Superior. Interface - Comunicação, Saúde, Educação, Botucatu, v. 15, n. 39, p. 1011-1024, out./dez. 2011. 
PEREIRA, E. M. A. (org.). Universidade e educação geral: para além da especialização. Campinas: Alínea, [2007]. (Coleção Educação em Debate).

RIBEIRO, M. L.; CUNHA, M. I. Trajetórias da docência universitária em um programa de pós-graduação em Saúde Coletiva. Interface - Comunicação, Saúde, Educação, Botucatu, v. 14, n. 32, p. 55-68, jan./mar. 2010.

RICHARDSON, R. J. Pesquisa social: métodos e técnicas. São Paulo: Atlas, 2007. VELLOSO, J. Mestres e doutores no país: destinos profissionais e políticas de pós-graduação. Cadernos de Pesquisa, São Paulo, v. 34, n. 123, p. 583-611, set./dez. 2004.

Recebido em: 03/03/2019 Aceite em: 25/07/2019 